\title{
The potential of OCT for assessing laser assisted removal of deposits from ceramic tiles
}

\author{
Magdalena Iwanicka ${ }^{1 \star}$, Jędrzej Musiela ${ }^{2}, J^{2}$ adwiga W. Łukaszewicz ${ }^{1}$, \\ Henryk Stoksik ${ }^{3}$, Marcin Sylwestrzak ${ }^{4}$ \\ 1 Institute for the Study, Restoration and Conservation of Cultural Heritage, Nicolaus Copernicus \\ University, ul. Sienkiewicza 30/32, 87-100 Toruń, Poland \\ 2 Restauro Sp. z o.o., ul. Wola Zamkowa 6, 87-100 Toruń, Poland \\ 3 Faculty of Ceramics and Glass, The Academy of Art and Design, Plac Polski 3/4, 50-156 Wrocław, \\ Poland \\ 4 Institute of Physics, Faculty of Physics, Astronomy and Informatics, Nicolaus Copernicus University, \\ ul. Grudziądzka 5, 87-100 Toruń, Poland \\ * Corresponding author: magiwani@gmail.com
}

\begin{abstract}
Optical Coherence Tomography (OCT), the technique of non-invasive imaging of transparent and semi-transparent sub-surface layers was employed to monitor the state of glazes of historic tiles before and after laser ablation trials. The laser used was Nd:YAG Thunder Art system from LightForArt (El. En. S.p.A.).

In this paper, OCT cross-sectional images of both fragments and preserved historic tiles before, during and after laser ablation are shown to examine the process of the removal of surface deposits as well as mid-twentieth century conservation coatings. In case of some of the ceramic fragments (donated to science) the destruction of the glaze layer after a few steps of laser cleaning was induced intentionally and then visualized with OCT.

The experiments performed confirmed that OCT is a potential diagnostic tool for the assessment and monitoring of laser removal of deposits from semi-transparent glazes on historic tiles, as well as enabled to define and identify specific risk factors for these objects, such as pre-existing cracks or delaminations within the glaze layer.
\end{abstract}

Keywords: optical coherence tomography (OCT), laser, ablation, cleaning, glazed ceramics, SEM-EDS

\section{Introduction}

Ceramic artefacts from archaeological sites suffer from a vast range of deteri oration phenomena, some of which are occurring in glaze layers. Such problems, caused mainly by long exposure to environmental factors, are: cracks, delaminations, pitting, all resulting eventually in the formation of losses within the glaze. Also surface dirt and old conservation coatings contribute to the complexity of present conservation issues. The cleaning of such objects is both difficult and controversial, since some conservators believe 
that the corroded glaze layer should not be removed. "Wet" cleaning or solvent cleaning of such artefacts is possible; nevertheless, it poses danger of transferring particles of unwanted materials into the porous structure of the object. Therefore, since during laser cleaning deposits evaporate from the surface and do not penetrate into fine cracks, laser ablation seems to be an adequate alternative to conventional cleaning. However, in some cases, laser cleaning may also be not safe for the object. Pre-existent destruction phenomena in glaze layer, such as delaminations and cracks, as well as raised temperature on the surface of glaze (lead based glazes have low melting point) may result in damages.

The aim of this work was to evaluate the applicability of Optical Coherence Tomography for following and controlling the process of laser removal of unwanted mineral deposits and secondary layers. As for our knowledge it is the first time that OCT (here in combination with SEM-EDS) has been used for progress assessment of laser cleaning tests on glazed ceramic objects.

It is important to note that the main intention of the authors of this experiment was to employ OCT as an aid for free-hand cleaning by a commercial laser system, which would be used in the typical restoration studio. Therefore, the emphasis was put on the early damage detection in glaze layers, which was possible thanks to the OCT data and not on developing new approaches to laser cleaning of ceramic tiles.

\section{Materials and methods}

\subsection{Investigated ceramic objects}

A group of medieval archeological ceramic tiles with various deterioration problems (both fragments and whole preserved tiles) with glazes semi-transparent to infra-red radiation were chosen from the collection of the District Museum in Torun, Poland. In this study, we present the results of experiments on three objects, all found in the archaeological site at the Teutonic Order Castle in Torun during the excavation works in 1958-1966. Their exact place of origin is, however, uncertain, since the castle ruins had been used as a wasteyard for the whole old city area from the middle $15^{\text {th }} \mathrm{c}$., when the castle was demolished, up to late $19^{\text {th }}$ century. Two tile fragments of uncertain time of origin (17 $7^{\text {th }}$ c.?) and one piece (with depiction of St. Dorothy, $15^{\text {th }} \mathrm{c}$.) were examined by means of macroXRF mapping and SEM-EDS scanning (on microsamples) in order to establish the technology of origin (stratigraphy and glaze composition) as well as surface morphology and state of preservation. The pieces were subsequently treated to laser cleaning tests with the aid of OCT as a tool to follow and assess the ablation process.

\subsection{Optical Coherence Tomography}

Optical Coherence Tomography (OCT) [1,2] is an optical interferometric non-contact and non-invasive technique of depth-resolved imaging within media scattering and/or absorbing near-infrared light moderately. A narrow beam of infrared light (spectral range: $770-970 \mathrm{~nm}$ ) penetrates the object and is scattered at its structural elements. Then it is brought to interference in a Michelson interferometer and a structure of the object along the beam (an A-scan) is reconstructed from the detected signal. This procedure is repeated line-by-line for the whole examined cross-section.

OCT's ability of scanning areas (up to 12 $\times 12 \mathrm{~mm}^{2}$ ) in order to obtain information about sequence, continuity and thickness of 
the surface and subsurface layers makes it especially suitable for assessment of removal of unwanted layers [3-7]. For examination whose results will be presented herein, a high resolution (ca $2 \mu \mathrm{m}$ axial resolution in material, $15 \mu \mathrm{m}$ lateral resolution) spectral domain OCT instrument utilising near infrared $(770-970 \mathrm{~nm})$ radiation of $0.8 \mathrm{~mW}$ power beam at the object was utilised.

Thanks to the motor-driven translation of the OCT head away from the examination region for a time of the laser ablation test and then back to the exactly same position, scans obtained before and after laser ablation can be correlated easily and compared in a straightforward manner. The OCT tomograms (Figs. 4-6) are shown in false colour scale with areas not-scattered or not reachable for light shown in black. Low scattering centres are shown in blue whereas high scattering - in warm colours (from green to red). The uppermost region in all tomograms is just an air above the object. Then the air-glaze interface is seen as a strong green line. Non-scattering glaze layer below is mostly black and finally the surface of strongly absorbing ceramic body is visible in bluish hue. Surface deposits and cracks strongly scatter the light and are well visible in green. Notice that the tomograms are vertically stretched for better readability. Scale bars in all the tomograms shown in the figures are equivalent to $200 \mu \mathrm{m}$ (in air) in both directions.

\subsection{Laser ablation tests}

For laser ablation of unwanted material an Nd:YAG Thunder Art system from Light For Art (El.En. S.p.A.) was operated at $1064 \mathrm{~nm}$. Laser pulses of 8 ns length and spot size $\approx$ $7 \mathrm{~mm}$ were used with repetition rate $7 \mathrm{~Hz}$. Different energy values and fluency ranges were used for different pieces:
Tile fragment $\# 1: \mathrm{E} \approx 600-700 \mathrm{~mJ}$; fluency $\approx 1.6-1.8 \mathrm{~J} / \mathrm{cm}^{2}$

Tile fragment $\# 2: \mathrm{E} \approx 500-610 \mathrm{~mJ}$; fluency $\approx 1.3-1.6 \mathrm{~J} / \mathrm{cm}^{2}$

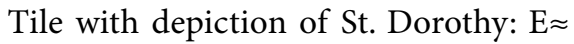
$350-370 \mathrm{~mJ}$; fluency $\approx 0.91-0.96 \mathrm{~J} / \mathrm{cm}^{2}$

\subsection{Additional analytical techniques MacroXRF scanning}

MacroXRF scanning is an imaging and semi-quantitative technique of elemental analysis which enables extended surface scans over thousands of square centimetres during a single examination. For this study, the M6 JetStream scanning system from Bruker Nano $\mathrm{GmbH}$ was employed [8]. It permits large surface scans - up to $70 \mathrm{~cm} \times 55 \mathrm{~cm}$ with lateral resolution up to $50 \mu \mathrm{m}$. It comprises a X-ray lamp working at $50 \mathrm{kV} / 600 \mu \mathrm{A}$ conditions with Rh anode and a polycapillary focusing optics. It is equipped with the $30 \mathrm{~mm}^{2}$ Silicon Drift Detector (SDD) with $\mathrm{Zr}$ window. An open-air system permits imaging elements of atomic numbers not lower than 16 (sulphur).

\section{SEM-EDS scanning}

Scanning electron microscope (SEM) from LEO Electron Microscopy Ltd, UK, model $1430 \mathrm{VP}$ was used for imaging of topography of the samples. Energy dispersive X-ray spectrometer (EDS) Quantax 200 (detector XFlash 4010) from Bruker AXS was utilised for elemental mapping of the samples' cross-sections.

\section{Results}

\subsection{Tile fragment \#1}

The fragment listed in this contribution as \#1 (MOT - P 72 from the District Museum 
in Torun, $17^{\text {th }}$ c.?) has a lead-based, copper tinted glaze on whitish engobe (Fig 1,2). The piece was laser cleaned in few spots using similar laser parameters (ca 600-700 mJ, fluency: $1.6-1.8 \mathrm{~J} / \mathrm{cm}^{2}$ ). Afterwards, macro XRF scanning was performed and finally four microsamples were collected, two from spots in uncleaned areas and two from spots located in cleaned areas showing different visual properties after the ablation tests (Fig. 1). calcium-rich layer on top of the glaze. The discontinuity of the surface marked by red and blue arrows in Fig. $2 \mathrm{~b}$ indicate that this layer is not a mere secondary deposit, but in fact a disintegrated upper layer of glaze, which accumulated calcium ions either from the surrounding or as a result of leaching of the deeper layers of the glaze.

Two different results of laser ablation tests on this object are presented in Figs. 3 and 4.

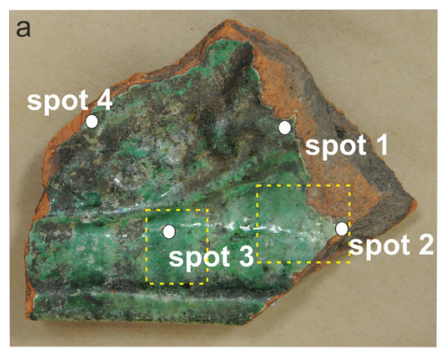

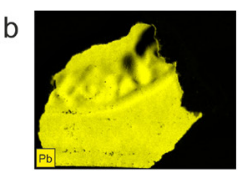

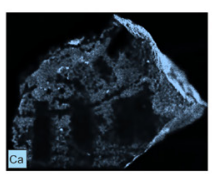

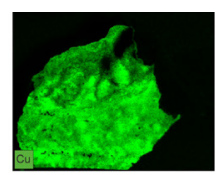

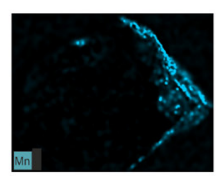

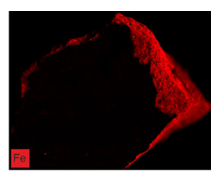

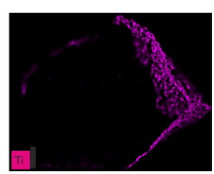

Fig. 1. a. Tile fragment \#1 in visible light after laser ablation tests. Dashed lines mark areas of laser ablation tests. White dots mark sample collection spots. b. Macro XRF scans after laser ablation tests.

Photography (Fig. 2a) of the cross-section of the sample collected from an uncleaned area (spot no 4, in Fig. 1a) reveals the stratigraphy of the tile piece: ceramic body with whitish engobe and green glaze. SEM image and EDS map (Fig. 2b,c) give insight into the
Both areas were cleaned with the same laser parameters in two steps. Only results after the second step are shown.

The area (around spot 2 in Fig. 1) shown in Fig. 3 was cleaned to a satisfactory extent, leaving glossy glaze layer. OCT tomograms a

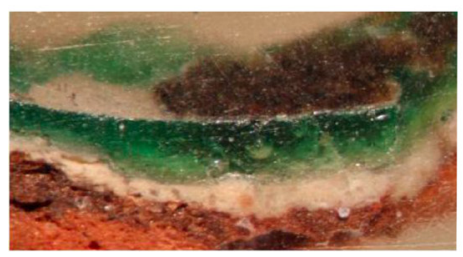

b

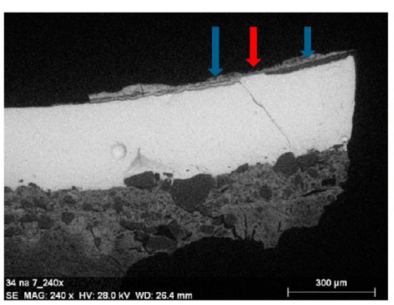

C

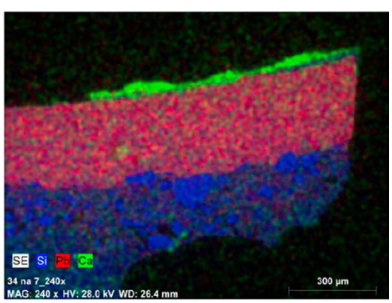

Fig. 2. Tile fragment \#1, spot no 4, uncleaned. a. Cross-section in reflected light microscopy: body, engobe and uneven green glaze are visible. b. SEM image. The arrows show primary level of glaze (red) as well as declined level (blue) due to disintegration processes and formation of black crusts. c. EDS map: Ca-rich layer of corrosion (marked green) and surface deposit (black crusts) is visible on top of the glaze layer (containing $\mathrm{Pb}$ - marked red). Si (shown in blue) indicates the engobe. 
a

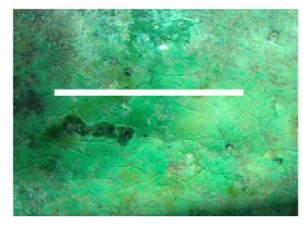

b

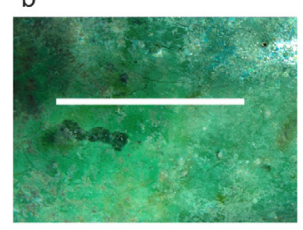

C

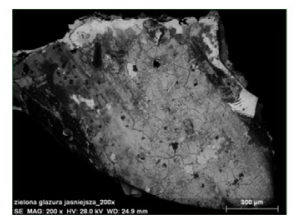

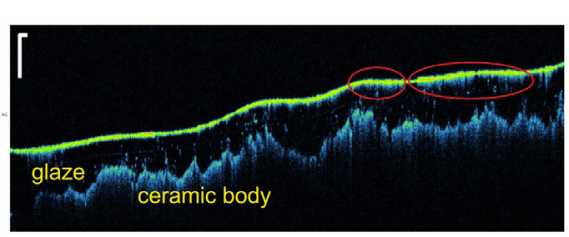

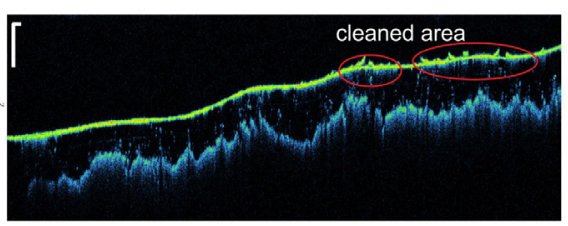

d

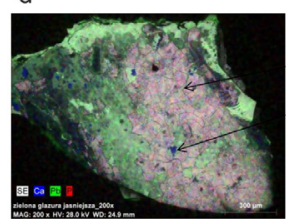

Fig. 3. Tile fragment \#1, spot no. 2 . The area cleaned to a desired extent, showing glossy glaze layer. a. Optical microscopy and OCT images collected before laser ablation. The white line in the microphotograph shows location of the OCT scan. Red ovals in the OCT tomogram mark surface deposits addressed during following laser ablation tests. b. Optical microscopy and OCT images collected after laser ablation, step 2 ( $\mathrm{E}=680$ $\mathrm{mJ})$. Red ovals marks surface deposits detached from the glaze. c. SEM image, after cleaning. d. EDS map, after laser ablation. Arrows mark calcium deposits. give insight into the laser ablation process. It is evident that the deposits (marked with red ovals in Fig. 3a), semi-transparent to the infra-red and thus coded in greenish hue in the tomograms get detached from the surface during laser treatment and are discernible as loose flakes (the tomogram was recorded before dry wiping of the surface) in Fig. 3b. In the SEM image (Fig. 3c) of the sample collected afterwards (spot no. 2, Fig. 1a) there are neither surface deposits nor ablation-related abrasions/losses visible. EDS map (Fig. 3d) shows concentration of calcium only locally and in the craquelure. All the results (microscopic photography, OCT cross-sectional images, SEM image and EDS map) show convergent results: the investigated area was effectively cleaned without damage to the glaze.

In the second experiment (Fig. 4) performed in a different area (around spot 3 in Fig. 1) surface deposits were completely removed, yet leaving the glaze matte and the surface rough, which is clearly visible in the OCT image (Fig. 4b). SEM image (Fig. 4c) and EDS map (Fig. 4d) reveal the removal of the disintegrated upper layer of glaze.

Dissimilar cleaning results observed in two areas (Fig. 3 and Fig. 4) of the tile fragment \#1 could have been due to the differences in the state of preservation of the glaze layer. Since we had found corroded glaze on this tile (see Fig. 2b, c), we could assume that the stage of deterioration varied in two cleaned areas. Another factor that should be taken into consideration is that the thickness (and IR absorption) of mineral deposit had varied in two ablated areas (which is visible in OCT images - see Figs. $3 a$ and $4 a$ ), which could have influenced the results of laser tests. 
a
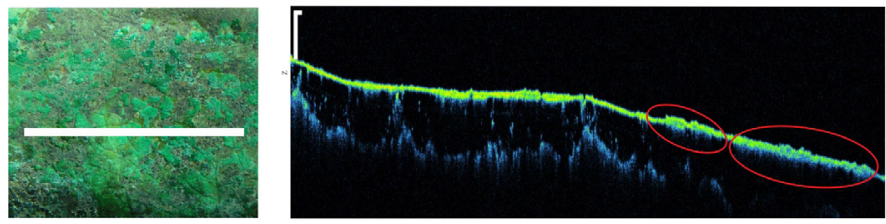

b
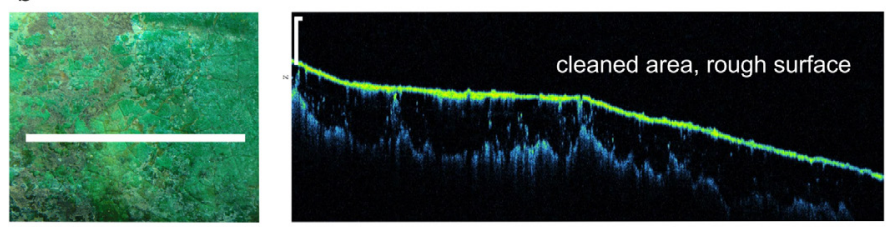

C

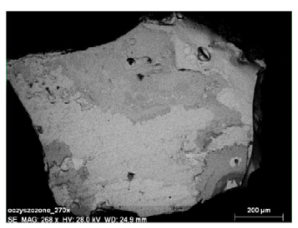

d

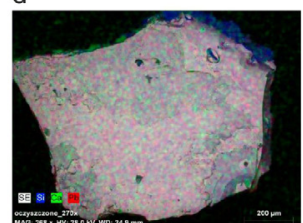

Fig. 4. Tile fragment \#1, spot no. 3. Area overcleaned, showing matte glaze layer with calcium-rich corrosion layer removed. a. Optical microscopy and OCT images before laser ablation. White line in the microphotograph shows location of the OCT scan. Red ovals in the OCT tomogram mark surface deposits addressed during following laser ablation. b. Optical microscopy and OCT images after laser ablation, step $2(\mathrm{E}=700 \mathrm{~mJ})$. c. SEM image, after laser ablation. d. EDS map, after laser ablation.

\subsection{Tile fragment \#2}

Tile fragment \#2 (MT/ZK-K-56, Fig. 5a) was executed with a similar technology as tile fragment \#1. For this piece only optical coherence tomography was used for the eval- uation of the laser ablation process. Surface deposits in this case were non-transparent to infra-red. This is why the ceramic body was not visible from under the glaze in the OCT tomogram collected before laser ablation tests (Fig. 5b). However, after the a
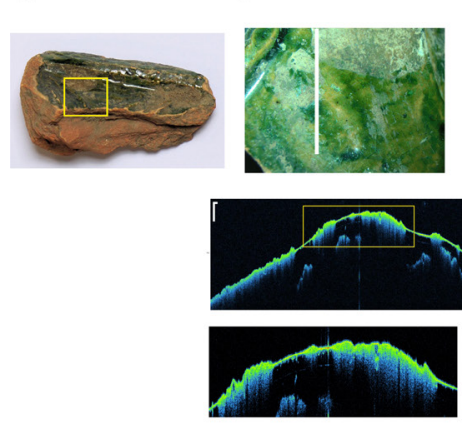

C

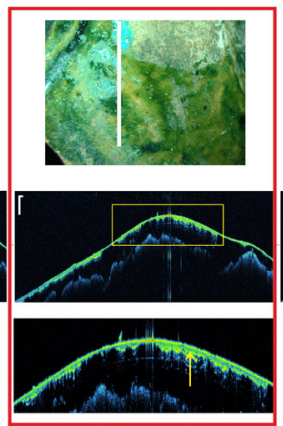

d
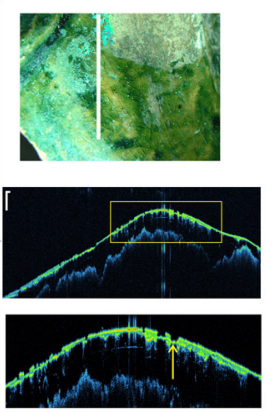

e
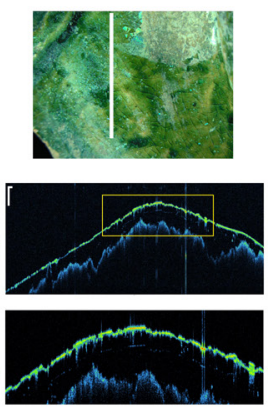

Fig. 5. a. Tile fragment \#2 in visible light. b-e. Microscopic photographs and OCT tomograms from the consecutive stages of laser ablation tests (b. before cleaning; $c$. after cleaning step 1, E=500 mJ; d. after cleaning step 2, E=560 mJ; e. after cleaning step 3, E=610 mJ); position of the OCT scans marked on the photographs with the white line. Red rectangle marks the most satisfactory result in the authors' opinion. Yellow arrows mark delaminations and following losses in the upper layer of glaze. 
first step of cleaning (Fig $5 \mathrm{c}$ ) the deposits were removed and both the glaze surface and glaze-body interface were clearly visible. Moreover, it was visible in the cross-sectional OCT image (Fig 5c) that the upper layer of glaze was delaminated (yellow arrows in Fig $5 c, d$ ) which was indicated by the high intensity of signal reflected at that interface. In step 2 and 3 intentional overcleaning was performed, and, as it had been anticipated, the delaminations became the source of losses and eventually of the rough surface (Fig. 5e).

\subsection{Tile with depiction of St. Dorothy}

Late $15^{\text {th }} \mathrm{c}$. tile with lead-based, copper tinted glaze (Fig. 6,7) was subject to some undocumented conservation treatments, resulting in the presence of a thick layer of hardly soluble synthetic resin coating. Additionally, OCT examination revealed the presence of dirt embedded under the coating (Fig. 6a).

The evaluation of the laser cleaning by means of OCT assessment was performed in a flat area of the background (red rectangle a

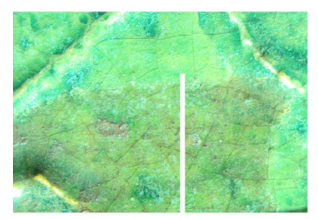

b

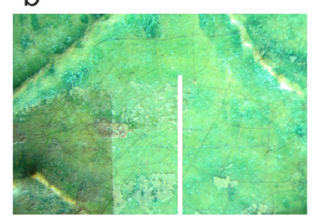

C

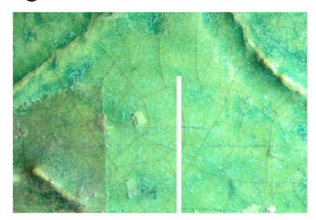

d

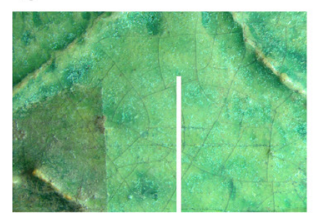

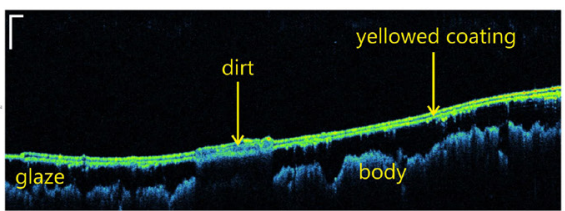
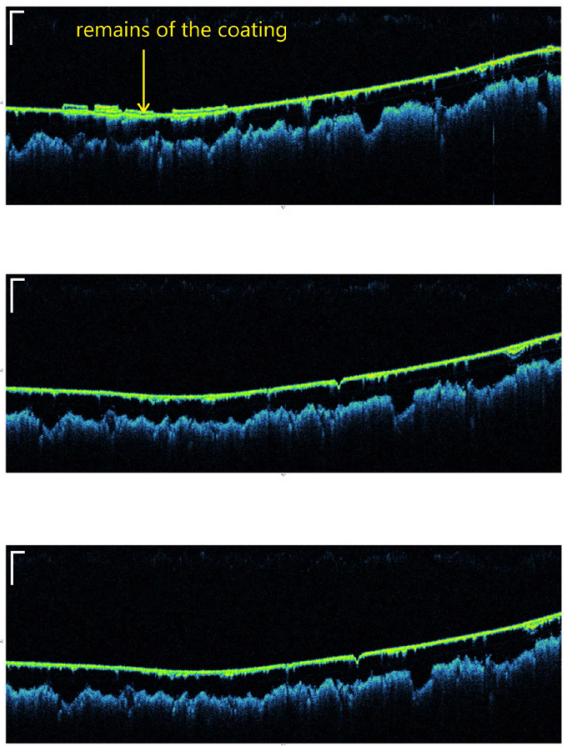
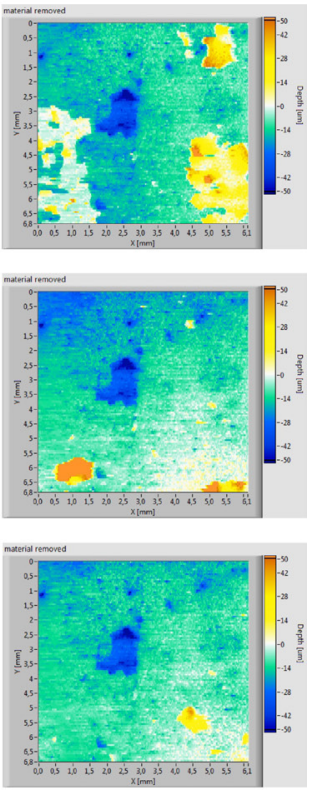

Fig. 6. The tile with a depiction of St. Dorothy. From the left: microscopic photographs, OCT tomograms and material removal maps from the consecutive stages of laser cleaning; positions of the OCT scans are marked on the photographs with white lines. a. before cleaning; b. after cleaning step 1, E=370 mJ; c. after cleaning step 2, E=350 mJ; d. after final swabbing with white spirit). 

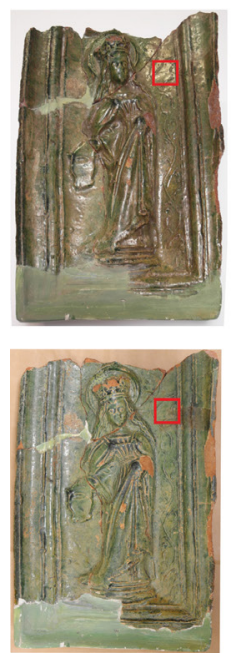
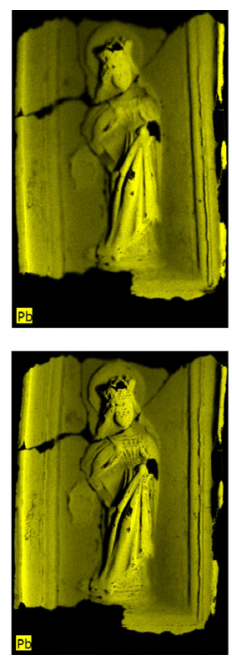
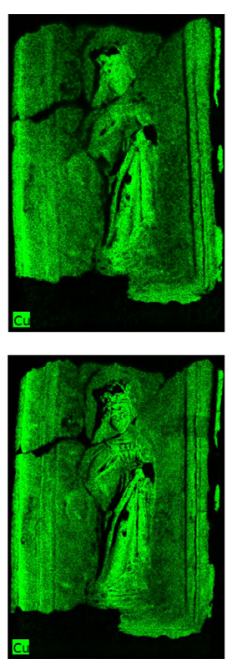
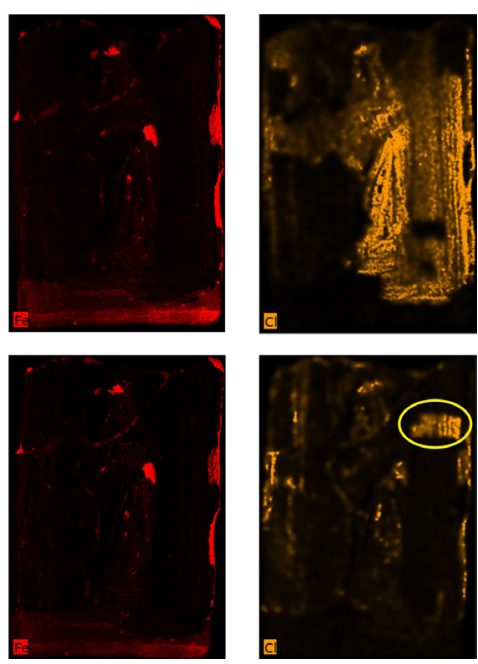

Fig. 7. The tile with a depiction of St. Dorothy. The tile in visible light with macro XRF scans before (upper row) and after (lower row) laser cleaning. Red rectangles in visible light photographs mark spot of the cleaning evaluation shown in Fig. 6. Yellow oval at chlorine map marks reference area, intentionally left uncleaned.

in visible light photographs in Fig. 7). OCT tomograms obtained before laser ablation (Fig. 6a) unfolded the good state of preservation of the glaze layer, lacking cracks or delaminations. After the first step of ablation (Fig. 6b), it is clear that the resin is mostly removed; however, some detached flakes still remain on the surface. These are removed during the second step (Fig. 6c) and the final wiping of the glaze with white spirit (Fig. 6d). Swabbing is routinely performed by the restorers at the end of the laser treatment; therefore, it had been included in the experiment. No damage to the glaze was recorded due to the laser treatment, as well as no decrease in the thickness of the glaze, which had been theoretically possible due to the evaporation of lead compounds with low melting point. It is also worth noting that in the chosen cross-sectional OCT image there is no visible difference between the surface after cleaning step 2 (Fig. 6c) and after swabbing with white spirit (Fig. 6d). Some loose particles of removed resin can be seen in the surface map (Fig. 6c) and it is evident that they are displaced during the swabbing (Fig. 6d).

For the steps 1,2 and after final wet cleaning additional maps of the removed material were created from the OCT data cubes. In order to do so, in the first place the surface elevation maps were generated from OCT data for every step and the OCT data cubes were corrected for refractive distortion. Since the removal of a coating usually causes some translation of the object, careful alignment of data sets was necessary, using the ceramic body, non-altered during the cleaning process, as a reference. Finally, the aligned surface elevation maps were subtracted to get a map of a removed material. In the maps cold colours (green, blue) show the decline of the surface level due to coating removal. Warm colours (yellow, orange) present the rise in the surface level - in this case resulting 
from the loose flakes of the ablated resin still present on the surface of the glaze.

Additionally, macro XRF scans of the object collected before and after cleaning (Fig. 7) aided in evaluation of the results of the ablation process. Chlorine maps (orange) show the effect of synthetic resin coating (chlorine-rich) removal, whereas lead (yellow) and copper (green) represent the state of glaze preservation before and after cleaning. The iron distribution map (red) shows, on the other hand, the areas of glaze losses, since the iron signal is detected from the ceramic body. The range of glaze losses did not grow larger after the laser treatment. The authors believe that such comparison is more informative than a mere analysis of the photographs of the tile, since the presence of the yellowed synthetic resin could have obscured visual analysis. The resin is "transparent" for X-ray radiation; therefore, minor losses of glaze present before cleaning and covered with the resin were still detectable in macro XRF scans.

\section{Discussion and conclusions}

In this study, we presented the first attempt to use optical coherence tomography as a progress assessment tool for laser ablation tests of semi-transparent glazes on historic tiles. According to the authors' knowledge, there are no systematic research results available on the absorption properties of historic glazes of various compositions. However, some indication on absorption properties of the glazed objects may be derived from the OCT results. To utilise these data for ablation experiments, it was necessary to choose laser wavelength from the same spectral range as used for OCT probing light. Here, from the OCT data, a conclusion was drawn that mineral deposits (on tile fragments \# 1 and \#2) were definitely more absorbing IR than the glazes. In case of the removal of the old resin coating, we had found a layer of dirt between the lacquer and the glaze. Therefore, some self-termination effect during the cleaning was expected. On the other hand, in case of fragments \#1 and \#2, where no strong absorption of the IR light in the glazes was found and deep penetration was thus envisaged, the authors intentionally wanted to create some destruction phenomena within the glazes to investigate the potential of OCT to detect such problems (intentional destruction was performed for the tile fragment \#2).

In conclusion, OCT proved suitable for the glazes transparent to near infrared. The thickness of glaze layer can be measured fast, instantly and non-invasively in many spots. The continuity of the surface can be evaluated prior to and after laser ablation and surface profiles can be compared in a straightforward way.

OCT tomograms and varnish removal maps do not only enable the evaluation of the amount of material removed as well as recording of the possible ablation-related damage, but they also help to define and identify specific risk factors for glazed ceramic objects. Such factors are pre-existing cracks or delaminations within the glaze layer, as well as areas of reliefs which are covered with much thinner layer of glaze than the flat background. The authors believe that such areas should be approached with greater caution.

\section{Acknowledgements}

The authors would like to thank Mrs Romualda Uziembło, Senior Curator and Head of the Archaeological Department of the District Museum in Torun for providing objects as well as valuable 
information on their archaeological background. Particular thanks should be given to dr Grażyna Szczepańska (Faculty of Chemistry NCU) for SEMEDS analyses. This research has been co-financed by H2020 IPERION CH project (contract number: 654028) and conducted with the use of the research infrastructure of Interdisciplinary Centre for Modern Technology of Nicolaus Copernicus University in Toruń, Poland, financed by Regional Operational Programme for Kujawsko-Pomorskie Voivodship (Project No.: RPKP.05.04.00-04-001/10).

\section{References}

[1] P. Targowski, M. Iwanicka, "Optical Coherence Tomography: its role in the non-invasive structural examination and conservation of cultural heritage objects-a review", Appl. Phys. A 106, (2012), 265-277, DOI: $10.1007 / \mathrm{s} 00339-011-6687-3$.

[2] Complete list of papers on application of OCT to examination of artwork may be found at http:// www.oct4art.eu: Optical coherence tomography for examination of works of art, (accessed 8.07.2017).

[3] J. Striova, R. Fontana, M. Barucci, A. Felici, E. Marconi, E. Pampaloni, M. Raffaelli, C. Riminesi, "Optical devices provide unprecedented insights into the laser cleaning of calcium oxalate layers", Microchemical Journal, 124, (2016), 331-337, DOI: 10.1016/j.microc.2015.09.005.

[4] M. Iwanicka, P. Targowski, E.A. Kwiatkowska, M. Sylwestrzak, "Application of optical coherence tomography for monitoring some conservation treatments", in: Lasers in the Conservation of Artworks IX (Proceedings of Lacona IX conference),
London, UK, September 7-10, 2011, D. Saunders, M. Strlič, C. Korenberg, N. Luxford, K. Birkhölzer (Eds.), Archetype Publications Ltd, London 2013, pp. 19-25.

[5] M. Iwanicka, D. Kończalska, P. Targowski, B.J. Rouba, "Non-Contact and Non-Invasive Monitoring of Overpaint Removal with Optical Coherence Tomography", in: New Insights into the Cleaning of Paintings: Proceedings from the Cleaning 2010 International Conference, M.F. Mecklenburg, A.E. Charola, R.J. Koestler (Eds.), Smithsonian Contributions to Museum Conservation III, Washington D.C. 2013 (extended abstract), pp. 27-29.

[6] P. Targowski, R. Ostrowski, J. Marczak, M. Sylwestrzak, E.A. Kwiatkowska, "Picosecond laser ablation system with process control by Optical Coherence Tomography", Proc. SPIE 7391, (2009), 7391G, DOI: $10.1117 / 12.827286$.

[7] M. Góra, P. Targowski, A. Kowalczyk, J. Marczak, A. Rycyk, "Fast spectral optical coherence tomography for monitoring of varnish ablation process", Proceedings of the international conference LACONA VII: - Lasers in the Conservation of Artworks, Madrid, Spain, September 17-21, 2007, M. Castillejo, P. Moreno, M. Oujja, R. Radvan, J. Ruiz (Eds.), CRC Press, Taylor \& Francis Group, London 2008, pp. 23-27.

[8] M. Alfeld, J. Vaz Pedrozo, M. van Eikema Hommes, G. Van der Snickt, G. Tauber, J. Blaas, M. Haschke, K. Erler, J. Dik, K. Janssens, "A mobile instrument for in situ scanning macro-XRF investigation of historical paintings", Journal of Analytical Atomic Spectrometry 28, (2013), 760, DOI: 10.1039/ c3ja30341a. 